\title{
BCL2 Family Genes Expression in Gynecological Diseases
}

\author{
Stefania Lasorella ${ }^{1 *}$, Alberto Verrotti ${ }^{1}$, Ilaria Brambilla ${ }^{2}$, Riccardo Castagnoli ${ }^{2}$, Gian Luigi Marseglia ${ }^{2}$ and Maria $^{2}$ \\ Laura Iezzi ${ }^{1}$
}

${ }^{1}$ Department of Pediatrics, University of L'Aquila, Italy

${ }^{2}$ Department of Pediatrics, University of Pavia, Italy

Submission: July 09, 2019 ; Published: July 18, 2019

*Corresponding author: Stefania Lasorella, Department of Pediatrics, University of L'Aquila, Italy

\begin{abstract}
BCL2 family proteins are a very well-studied protein group for their critical role in cellular apoptosis. Apoptosis is involved in many biological phenomena and it is the basis of normal cellular homeostasis. It depends on a complex series of signals that are necessary for the homeostasis of our body. In this complex mechanism is involved a large family of oncogenes and tumor suppressor genes whose altered operation can lead to serious tissue disorders. Modifications of its complex processes have been recognized as responsible for different human pathologies including cancer, autoimmunity, neurodegenerative disorders and diabetes. Our review focuses on the normal functions and deregulation of BCL2 family genes in different gynecological pathologies: uterine congenital malformation, metabolic alterations (insulin-resistance and hyperandrogenemia), effect on ovarian follicles and endometrium proliferation. Certainly the connection between hormone alterations and interference with normal cell cycle are much investigated but further studies are necessary to better understand dysmetabolic pattern in which BCL2 members are involved in order to implement, where possible, a direct or indirect therapy aiming to restore the altered balance.
\end{abstract}

Keywords: BCL2 family genes; Gynecological diseases; Cancer; PCOS

Abbreviatation: TRADD: Tumor Necrosis Factor Receptor Type-1-Associated; DEATH: Domain Protein; FADD: Fas-Associated Protein With Death Domain; SMAC: Or DIABL0; APAF1: Apoptotic Protease Activating Factor; XIAP: X-Linked Inhibitor Of Apoptosis Protein; APAF1: Apoptotic Protease Activating Factor-1; LH: Luteinizing Hormone; FSH: Follicle-Stimulating Hormone; DHEA: Dehydroepiandrosterone; DHEAS: Dehydroepiandrosterone Sulphate; IRS1: Insulin Receptor Substratr-1; IRS2: Insulin Receptor Substratr-2; Pl3k: Phosphatidylinositol-4,5Bisphosphate 3-Kinase; AKT: Protein Kinase B; IR: Insulin Receptor; Mi 125b: Microrna; FLIP: Cellular FLICE-Like Inhibitory Protein; FAS/FASL: Apo-1 0 CD95/Apo-1L O CD95L; GNRH: Gonadotropin-Releasing Hormone; FSH: Follicle-Stimulating Hormone; DHEAS: Dehydroepiandrosterone Sulphate; P450c1a: Cytochrome P450c1a; AKT: Protein Kinase B; GLUT4: Glucose Transporter Type4; IR: Insulin Receptor; IRS2: Insulin Receptor Substratr-2; P: Phosphorilated; 14.3.3: 14.3.3 Proteins; XIAP: X-Linked Inhibitor Of Apoptosis Proteins; INS: Insulin

\section{Introduction}

BCL2 family proteins are a group of proteins well investigated for their role of "judge of apoptosis". Apoptosis is considered a vital phenomenon of various biological processes including normal cell turnover, normal development and function of immune cells and appropriate response to hormone action. All these functions are essential for tissues homeostasis and an escape from these mechanism can lead to an uncontrolled cellular growth and is consequently linked to multiple human diseases, including cancer, autoimmunity, neurodegenerative disorders and diabetes. Members of BCL2 family have either pro- or anti-apoptotic activities and their functions depend on interaction and modulation with other metabolic pathways; a toxic and oxidative microenvironment can activate the molecular intrinsic pathway with imbalances of anti- and pro-apoptotic expression with abnormal survival. In particular, we focused our attention on BCL2 modulation in some gynecological conditions characterized by dysembryogenesis, hyperandrogenism and hyperinsulinism. All these conditions create a microenvironment that alters the expression of BCL2 leading to alteration of apoptosis. The aim of this review is to highlight the molecular conditions and the clinical implications of BCL2 impaired expression.

\section{BCL2 Family Pathway}

\section{General overview}

The term B-cell lymphoma 2 (BCL2) gene was originally coined in by Vaux et al. [1] to nominate the oncogene product derived from the translocation $t(14 ; 18)$ where the BCL2 gene on the chromosome segment 18q21 is juxtaposed with the immunoglobulin heavy chain locus at 14q32 [2]. This translocation was originally highlighted in a number of follicular lymphomas 


\section{Journal of Gynecology and Women's Health}

and rise to a gene that overexpresses its natural anti-apoptotic function promoting survival cells without cytokines impulse [3]. The anti-apoptotic BCL2 corresponding protein consists of 26 $\mathrm{kDa}$ and it is localized to the outer membrane of mitochondria, where it plays an important function in ruling membrane permeabilization, promoting cellular survival and modulating the actions of other pro-apoptotic proteins; however, the greatest moTable 1: Members of BCL2 family in Homo Sapiens. lecular knowledge have underlined that BCL2 family is formed by a number of evolutionarily conserved protein divided into anti-apoptotic protein such as BCL2 and BCL-extra-large (BCLXL), pro-apoptotic activators (BH3 only, BID, BIM, BAD, NOXA PUMA) and in pro-apoptotic multi-domain effectors (BAX, BAK, BOK) [4,5] (Table 1).

\begin{tabular}{|c|c|c|c|}
\hline Name Gene & Location & Full Name/ Aliases & Function \\
\hline \multicolumn{4}{|c|}{ Proapoptotic- BH3-Only } \\
\hline BID & $22 q 11.21$ & $\begin{array}{l}\text { BH3 interacting domain death } \\
\text { agonist }\end{array}$ & $\begin{array}{l}\text { This protein heterodimerized with either agonist BAX or antagonist BCL2, It } \\
\text { is a mediator of mitochondrial damage induced by caspase- } 8 \text {. }\end{array}$ \\
\hline BAD & $11 \mathrm{q} 13.1$ & $\begin{array}{l}\text { BCL2 associated agonist of cell } \\
\text { death }\end{array}$ & $\begin{array}{l}\text { This protein positively regulates cell apoptosis by forming heterodimers with } \\
\text { BCLXL and BCL2, and reversing their death repressor activity; proapoptotic } \\
\text { activity of this protein is regulated through its phosphorylation. }\end{array}$ \\
\hline BIM & 2q13 & BCL2 like 11 BAM; BOD & $\begin{array}{l}\text { This protein interact with other members of the BCL-2 protein family and to } \\
\text { act as an apoptotic activation. }\end{array}$ \\
\hline PUMA & $19 \mathrm{q} 13.32$ & $\begin{array}{l}\text { BCL2 binding component } 3 \text { JFY1; } \\
\text { BBC3; JFY-1 }\end{array}$ & $\begin{array}{l}\text { This protein cooperates with direct activator proteins to induce mitochondri- } \\
\text { al outer membrane permeabilization and apoptosis, inducing mitochondrial } \\
\text { dysfunction and caspase activation. }\end{array}$ \\
\hline BMF & $15 q 15.1$ & BCL2-modifying factor & This protein bind BCL2 proteins and function as an apoptotic activator \\
\hline \multicolumn{4}{|c|}{ Proapoptotic- Multidomain (BH) } \\
\hline BAX & $19 \mathrm{q} 13.33$ & $\begin{array}{l}\text { BCL2 associated X, apoptosis } \\
\text { regulator BCL2L4 }\end{array}$ & $\begin{array}{l}\text { This protein forms a heterodimer with BCL2, and functions as an apoptotic } \\
\text { activator. This protein increase the opening of, the mitochondrial voltage-de- } \\
\text { pendent anion channel (VDAC), which leads to the loss in membrane potential } \\
\text { and the release of cytochrome c }\end{array}$ \\
\hline BAK & $6 \mathrm{p} 21.31$ & $\begin{array}{l}\text { BCL2 antagonist/killer } 1 \text { CDN1; } \\
\text { BCL2L7; BAK-LIKE }\end{array}$ & $\begin{array}{l}\text { This protein localizes to mitochondria, and functions to induce apoptosis. } \\
\text { It accelerates the opening of the mitochondrial voltage-dependent anion } \\
\text { channel, which leads to a loss in membrane potential and the release of cyto- } \\
\text { chrome c. }\end{array}$ \\
\hline ВOK & $2 q 37.3$ & $\begin{array}{l}\text { BCL2 family apoptosis regulator } \\
\text { BOKL; BCL2L9 }\end{array}$ & $\begin{array}{l}\text { This protein form homo- or heterodimers, and act as anti- or proapoptotic } \\
\text { regulators that are involved in a wide variety of cellular processes }\end{array}$ \\
\hline BCL2L14 & $12 \mathrm{p} 13.2$ & BCL2 like 14 & Overexpression of this gene has been shown to induce apoptosis in cells \\
\hline BCL2L13 & $22 \mathrm{q} 11.21$ & $\begin{array}{l}\text { BCL2 like } 13 \text { MIL1; BCL-RAMBO; } \\
\text { BCL2-L-13 }\end{array}$ & $\begin{array}{l}\text { This gene encodes a mitochondrially-localized protein with conserved B-cell } \\
\text { lymphoma } 2 \text { homology motifs. Overexpression of the encoded protein results } \\
\text { in apoptosis. }\end{array}$ \\
\hline \multicolumn{4}{|r|}{ Antiapoptotic } \\
\hline BCL2 & $18 q 21.33$ & $\begin{array}{l}\text { BCL2, apoptosis regulator } \\
\text { PPP1R50 }\end{array}$ & $\begin{array}{l}\text { This gene encodes an integral outer mitochondrial membrane protein that } \\
\text { blocks the apoptotic death. }\end{array}$ \\
\hline BCLXL & 20q11.21 & $\begin{array}{l}\text { BCL2 like } 1 \text { BCLX; BCL2L; BCL-X; } \\
\text { PPP1R52; BCL-XL/S }\end{array}$ & $\begin{array}{l}\text { The proteins encoded by this gene are located at the outer mitochondrial } \\
\text { membrane, and have been shown to regulate outer mitochondrial membrane } \\
\text { channel (VDAC) opening. }\end{array}$ \\
\hline BCL2L2 & $14 \mathrm{q} 11.2$ & $\begin{array}{l}\text { BCL2 like } 2 \text { BCLW; BCL-W; } \\
\text { PPP1R51; BCL2-L-2 }\end{array}$ & $\begin{array}{l}\text { The proteins of this family form hetero- or homodimers and act as anti- and } \\
\text { pro-apoptotic regulators. }\end{array}$ \\
\hline MCL1 & $1 \mathrm{q} 21.2$ & $\begin{array}{l}\text { BCL2 family apoptosis regulator } \\
\text { TM; EAT; MCL1L; MCL1S; MCL-1; } \\
\text { BCL2L3; MCL1-ES; BCL2-L-3; } \\
\text { MCL1/EAT }\end{array}$ & $\begin{array}{l}\text { Alternative splicing results in multiple transcript variants. The longest gene } \\
\text { product (isoform 1) enhances cell survival by inhibiting apoptosis while the } \\
\text { alternatively spliced shorter gene products (isoform } 2 \text { and isoform 3) pro- } \\
\text { mote apoptosis and are death-inducing. }\end{array}$ \\
\hline BCL2L10 & $15 q 21.2$ & $\begin{array}{l}\text { BCL2 like } 10 \text { BOO; DIVA; BCL-B; } \\
\text { BCL2-L-10 }\end{array}$ & $\begin{array}{l}\text { Overexpression of this gene has been shown to suppress cell apoptosis pos- } \\
\text { sibly through the prevention of cytochrome } \mathrm{C} \text { release from the mitochondria, } \\
\text { and thus activating caspase- } 3 \text { activation. }\end{array}$ \\
\hline
\end{tabular}

Structure, localization and communication between members of BCL2 family: Members of the BCL2 possess one or more of four BH domains (BCL2 homology motifs) and adopt similar globular structures which is a helical bundle surrounding a central hydrophobic core; this folds generates a hydrophobic

surface groove delineated by a $\alpha$-helices and this groove constitutes a crucial interface for interaction with the BH3 domain which are the promoters of the gene [6]. Interactions between BCL2 members are complex; the mechanism provides that products of effector genes, closely associated with the mitochondrial 
membrane, if stimulated by BH3-only activators (BIM,BID,PUMA), promote the formation of pores in the mitochondrial membrane irreversibly activating the killing program. These activators only contain BH3 amphipathic helix which mediates their interaction with the groove of multi-domain BCL2 family members. Furthermore, BCL2 can directly influence effectors to prevent mitochondrial activation $[7,8]$. BCL2 family proteins are widely distributed in body tissues.

Structurally BCL2 and BCLXL are largely associated with outer mitochondrial membrane and endoplasmic reticulum (ER) through a C-terminal transmembrane domain consisting of a hydrophobic $\alpha$-helix which functions as a membrane insertion de- vice [9]. Regarding other members of gene product, BAK (BCL2 antagonist/killer1) is also localised to the outer mitochondrial membrane via its $\mathrm{C}$-terminal transmembrane domain, while BAX (BCL2 associated X, apoptosis regulator) inactive form is mainly found in the cytosol with a small fraction tethered to the outer mitochondrial membrane; only $10-15 \%$ of BAK and BAX reside at the ER [10]. The anti-apoptotic action is mediated by BCL2, BCLXL, BCLW [11], MCL-1 (found largely on the outer mitochondrial membrane) and BCLB (that can interact with BAX but not $\mathrm{BAK})$, that maintain the permeability of the mitochondrial membrane preventing the release of cytochrome c [12] and, consequently, preventing the activation of apoptotic protease activating factor-1 (APAF-1) [13].

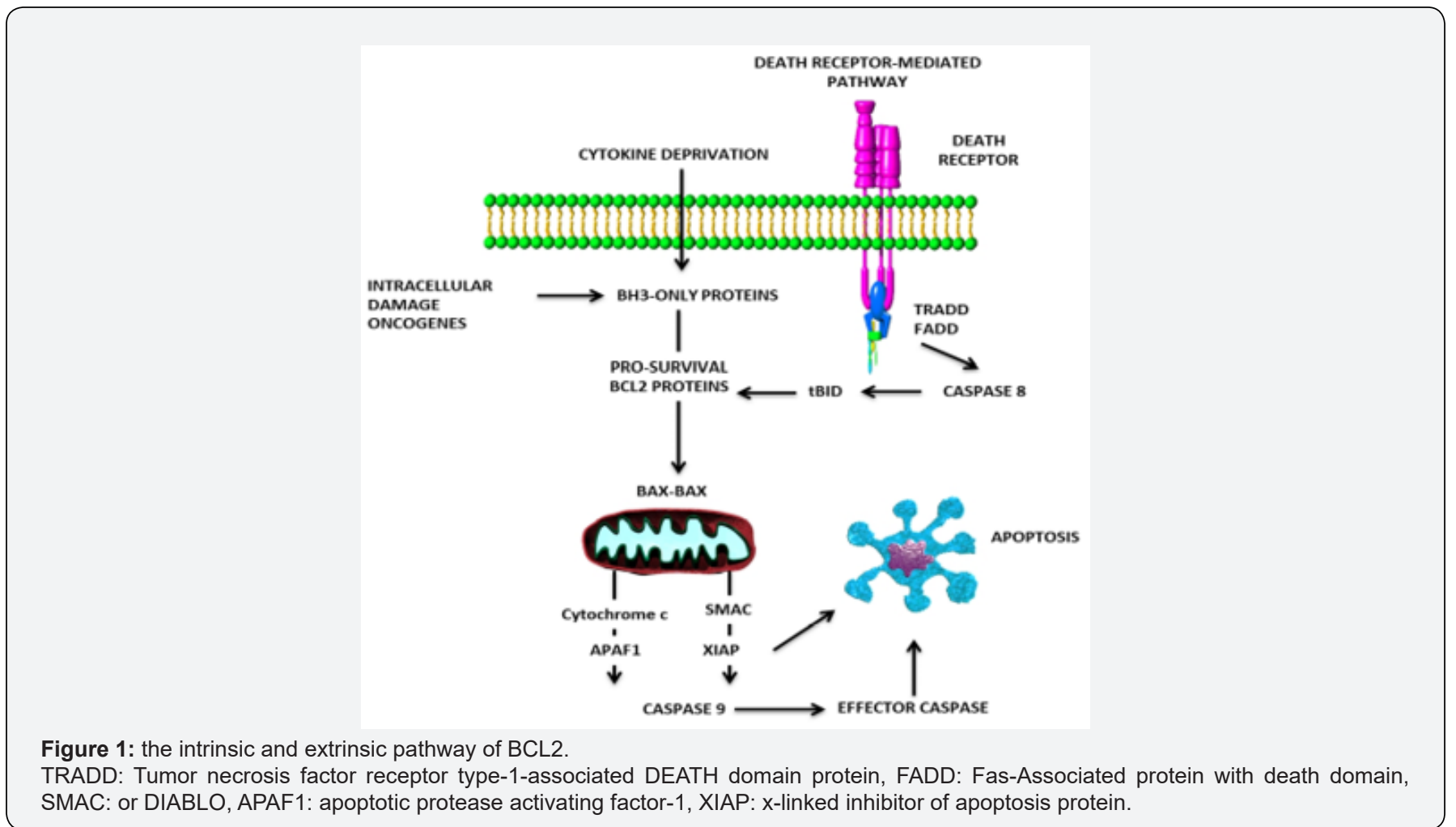

APAF-1in turn promotes caspase 9 and simultaneously the activation of SMAC (second mitochondria-derived activator of caspase) released from mitochondria; in addition APAF-1 and SMAC together block the caspase inhibitor XIAP (X-linked inhibitor of apoptosis protein) [14]. To this pathway shall be added the extrinsic pathway stimulated by Tumor Necrosis Factor family that activating Fas-Associated Protein with Death Domain (FADD) and Tumor Necrosis Factor receptor type 1-associated Death Domain (TRADD), localized on the plasma membrane, lead to caspase 8 activation. Caspase 8 operates the proteolysis of BID (BH3 interacting-domain death agonist) that interacts with the effector BAX that makes a structural change; this change consists in exposure of cryptic $\mathrm{N}$-terminal residues with oligomerization [15], and in engaging and drilling the outer mitochondrial membrane accelerating the opening of the mitochondrial voltage-dependent anion channel, with releasing of cytochrome $c$ and other pro-apoptotic factors [16]. In addition, also BAK) can lead to a loss in membrane potential contributing to the cytochrome $\mathrm{c}$ release. Moreover, other pro-apoptotic factors are released such as second mitochondria-derived activator of caspase/direct inhibitor of apoptosis-binding protein (SMAC/DIABLO) [17] (Figure 1). Survival of cells was considered to be regulated by a ratio of anti-apoptotic and pro-apoptotic BCL2 family proteins. The phosphorylation of even of just one of these members is a critical event that can alter members' behavior damaging this complex system.

\section{Impaired BCL2 Family in Gynecological Disease}

\section{Congenital uterine malformation}

Apoptosis has a critical role in postimplantation embryos. It is involved in eliminating abnormal or non-functional cells, sculpting structures, eliminating unwanted structures, and controlling cell numbers. Several teratogens have also been associ- 
ated with distortions in the regulation of apoptosis in the embryo and deregulation of BCL2 family plays obviously a critical role [18]. For these reasons, the importance of normal expression of BCL2 family members has been evaluated in congenital uterine malformations: bicornuate uterus is the result of a failure of Müllerian ducts fusion and the reabsorption of the vagino-uterine septum characterized by a deep fundal indentation $>1 \mathrm{~cm}$ between the horns, with a central myometrium covered by endometrium [19]. The American Fertility Society includes bicornuate uterus in the class IV (fusion) defects, where there is a partial fusion of the Müllerian ducts. In uterine development, BCL2 members are responsible for the regression of the central septum through a process of apoptosis: the mechanism provides deregulation of the gene that normally protects against apoptosis.

Mutation or phosphorylation of the members are sufficient to prevent the normal downregulation of the gene resulting in anomalies of development. This alteration has been highlighted in 4 human foetal uteri using a monoclonal antibody for BCL2 and immunohistochemical analysis [20]. The prevalence of these congenital anomalies was estimated to be $6.7 \%$ in the general/ fertile population, $7.3 \%$ in the infertile population and $16.7 \%$ in patients with recurrent miscarriage [21]. Often, in adolescence, the diagnosis is performed for the presence of primary amenorrhea or alterations of the menstrual cycle. These disturbances have negative reproductive consequences (premature birth, foetal abnormalities and also infertility).

\section{Impaired BCL2 family in metabolic disorders}

In the ovary, correct glucose metabolism, steroidogenesis, cell growth and differentiation require an adequate stimulation by insulin, gonadotropins and insulin-like growth factor-1 (IGF1). In these correct functions BCL2 family is largely involved, directly or not, in metabolic pathways to allow the physiological and cyclical changes of follicles and endometrium. In the following section we explain a complex and not well defined interface between insulin pathway and BCL2 family.

Normal insulin pathway: structures and cellular response: Although known as a major anabolic hormone, insulin produces a variety of biological functions, including stimulation of mitogenic responses such as cell growth and division and inhibition of apoptosis through phosphorylation processes [22]. The binding of insulin to its cell surface transmembrane receptor, triggers signaling events including activation of Phosphoinositide 3-Kinase/ Protein Kinase B (PI3K/AKT) pathway that is the principal intracellular way for regulation of the cell cycle, reducing apoptosis and allowing proliferation; moreover, insulin action is responsible for activation of Mitogen Activated Protein Kinase (MAPK), directly involved in cellular responses to different stimuli, such as mitogens, osmotic stress, heat shock and pro-inflammatory cytokines promoting genes expression [23].

The insulin receptor (IR) belongs to a family of Protein Tyro- sine Kinase Receptors that include also IGF-I, Epidermal Growth Factor, Fibroblast Growth Factor and cytokine receptors. Insulin possesses two asymmetric receptor-binding surfaces nominated "S1" (classic site) and "S2" (novel site) [24] and together both sites generate high-affinity insulin binding that activates the tyrosine kinase receptor. IR is encoded by INSR gene composed of 22 exons; it is localized on human chromosome 19p13.3-p13.2 and consists of two extracellular alpha-subunits and two beta-subunits [25]. The $\alpha$-subunits are entirely extracellular and create the ligand-binding sites, while $\beta$-subunit contains a transmembrane-spanning segment and an intracellular tyrosine kinase portion. Through an alternative splicing mechanism of the exon-11, two IR isoforms are generated: IRA that has no residues encoded by exon- 11 and IRB that includes the 12 amino acid residues encoded by exon-11. IRB binds only insulin with high affinity, while IRA binds both insulin and IGF1 with about equal affinity. IRB is more represented in the classic insulin target tissues (adult liver, muscle, and adipose tissues) while IRA predominates in foetal tissues, the adult central nervous system, and hematopoietic cells [26]. Clinical tests and evaluation of insulin-receptor mutations have highlighted the importance of tyrosine phosphorylation in the mechanism of insulin action [27].

The intracellular portion of insulin-receptor $\beta$-subunit is composed of three distinct regions that contain tyrosine phosphorylation sites. Infrequent oscillation from the "closed" to an "open" conformation in the basal state is associated to complementary changes in the $\alpha$-subunits, which can be stabilized definitively on insulin binding to accelerate adenosine triphosphate (ATP) entry and to stimulate auto-phosphorylation of Tyr1162 and subsequently to Tyr1158, resulting in a bis-phosphorylated and active kinase. Once the insulin receptor is activated, it phosphorylates a particular site (such as pp185) localized on insulin receptor substrates 1 and 2 (IRS1, IRS2). These early steps in insulin action are essential for the metabolic effects, playing an important role in basic cellular functions, such as growth and metabolism $[28,29]$. IRSs contain an N-terminal region homology (PH) domain, a phosphor-tyrosine binding (PTB) domain and several C-terminal multiple sites of tyrosine phosphorylation; $\mathrm{PH}$ domain is involved in targeting proteins to the appropriate cellular location or is responsible for interaction with other substrates [30,31]. In mammals, IRS1 and IRS2 are widely expressed in tissues, including the brain, muscle, heart, adipocyte, kidney, mammary gland and also in ovary and are directly responsible for increasing the high affinity glucose transporter (Glut4) molecules on the outer membrane of insulin-responsive tissues and for activating PI3K/AKT/mTOR pathway that is an intracellular signaling pathway important in regulating the cell cycle $[32,33]$.

Furthermore, another pathway stimulated by insulin is mTOR pathway which comprises a serine/threonine protein kinase that regulates cellular processes including proliferation, growth, survival and transcription, promoting in turn the activation of insulin and insulin-like growth factor 1 receptors [34,35]. Moreover, mTOR is activated by mitogenic-responsive pathways (Ras/ 
ERK, PI3K/Akt) in a directly proportional to the availability of intracellular energy and nutrients. Otherwise, mTOR is negatively regulated by 5' AMP-activated protein kinase (AMPK), sensor of intracellular adenosine nucleotide levels, which is activated on ATP decrease; when a cell is energetically stressed, the increased AMP concentration causes activation of AMPK with displace of ATP from the exchangeable sites, protecting the enzyme against dephosphorylation of the phosphothreonine residue with an increased activity [36]. Active AMPK inhibits cellular growth through the suppression of mTOR pathway inhibiting proliferative functions and these mechanisms have been highlighted in the ovary where it is demonstrated that the presence of AMPK is essential for follicles development and for promotion of ovarian angiogenesis necessary to ovary growth $[37,38]$.
Phosphorylation of BCL2 members: Phosphorylation by tyrosine kinases IR is an critical event that regulates the anti and pro-apoptotic effects of BCL2 family members; in particular the PI3K-Akt pathway and protein kinase A are implicated [39]. After receptor stimulation by insulin, IRS1 modulates BCL2 members activity thought phosphorylation at the loop domain, blocking apoptosis; in hepatocellular carcinoma cell lines it was observed an overexpression of IRS1 and an increased rate of growth associated with resistance to apoptosis è [40]. In addition, pro-apoptotic BAD function is mainly regulated by the phosphorylation of three evolutionary conserved serine residues, in particular one named S155; if not phosphorylated BAD heterodimerized with BCL2 promoting apoptosis but when it is phosphorylated, it is sequestered in cytosol, by binding 14-3-3, with inactivation of its killing duties [41,42] (Figure 2).

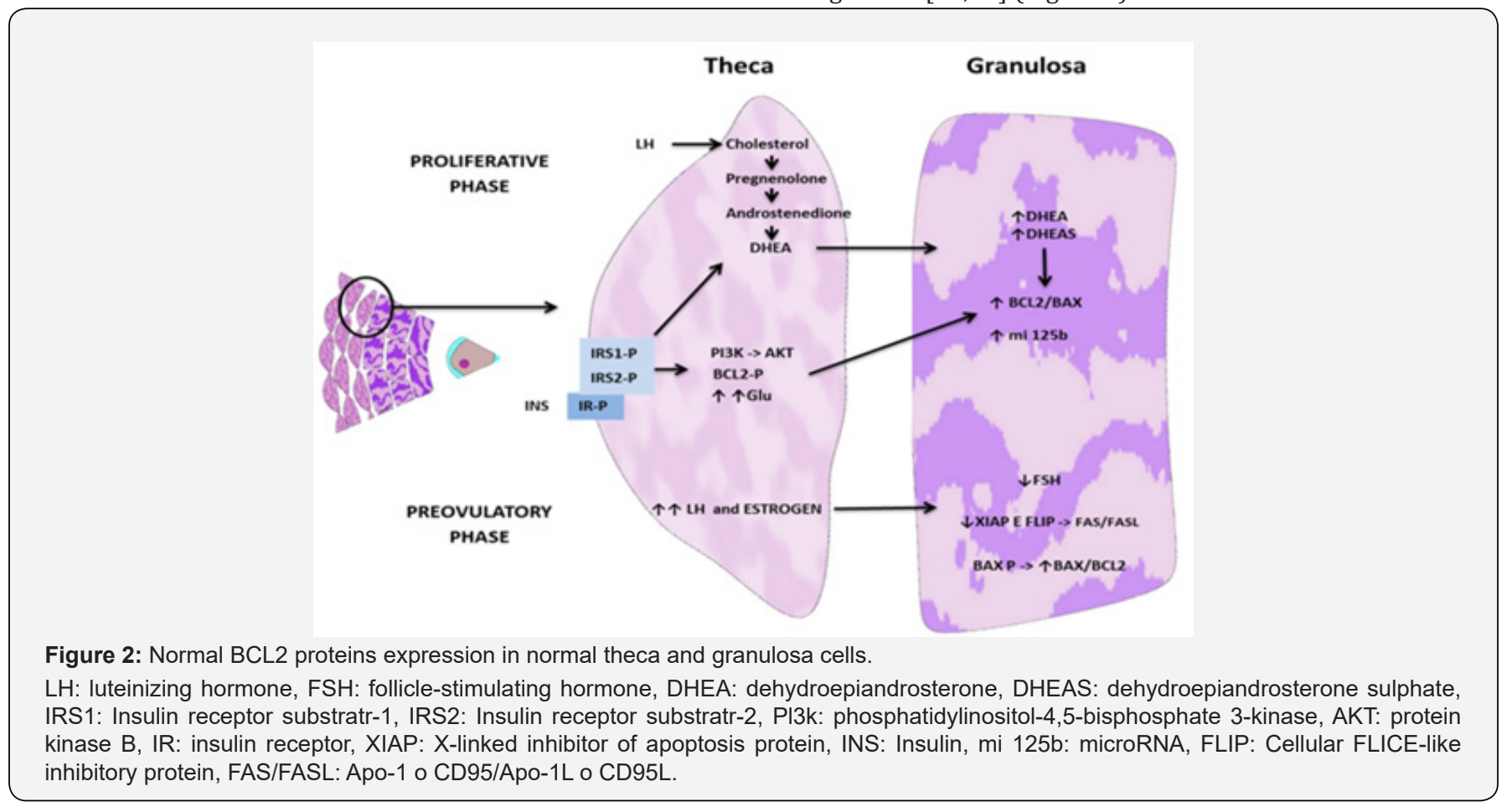

Abnormal insulin pathway in ovary: Since ovary is the most dynamic of the endocrine organs, glucose is an important energy substrate for the generation of ATP necessary to metabolic and physiological functions [43]. Physiologically, the concentration of glucose is higher in follicular fluid of large follicles for increased metabolism. For these reasons, IRs have a strong presence in granulosa and thecal cells where, if stimulated by insulin, it encourages proliferation of granulosa cells and steroidogenesis in theca cells [44]. Different stimuli can modify IRSs expression and it was been well characterized that IRS proteins regulate many important ovarian functions through insulin/IGF-1. In fact, abnormal level of insulin leads to impaired development of oocyte [45]. In particular, IRS2 has been known to mediate metabolic and reproductive functions and several studies conducted on null female mice have shown that IRS2 expression may be vital for the growth and metabolism in ovarian follicular cells
$[46,47]$. In healthy ovaries, granulosa cells express high levels of IRS2 and are directly proportional to FSH level.

A study conducted on human and rat granulosa cells, isolated from aspirated follicular fluid, have shown that FSH stimulation results in IRS2 gene expression and protein production, whereas luteinizing hormone-like activity of human chorionic gonadotropin does not result in up-regulation of IRS2 expression in granulosa cells; moreover, IRS2 expression in response to FSH was observed to be defective in significant number of PCOS patients and this could lead to follicular growth arrest in preovulatory follicles and consequently infertility in PCOS patients. All these data suggest that IRS2 function is fundamental; the mere presence of IRS1 is not sufficient to preserve follicular function due to the impaired Akt activation; IRS1 knockout mice had no defect in phosphotyrosine (PY)-associated PI3K activity because the increase in IRS2 levels, whereas IRS2 knockout mice exhibits 
decreased PY-associated PI3K activity [48-50]. IRSs stimulate diverse signal cascades and consequently insulin actions; for these reasons, altered expression may be responsible for impaired insulin action, imbalance and abnormal ovarian functionality in Polycystic Ovary Syndrome (PCOS) with impaired follicles growth and increased androgen secretion by thecal and stromal cells. Equally IRS transmit insulin signals to BCL2, regulating cell survival mainly through phosphorylation of BCL2. When associated with the loop domain of BCL2, IRS1 up-regulates its anti-apoptotic function. Normally in the ovary IRS1 is largely expressed in follicle, IRS2 expression is most performed in theca interna cells. In women with PCOS, IRS1 expression is decreased in the granulosa cells while expression of IRS2 is increased in theca interna cells and appear in granulosa cells; IRS2 was shown to be an anti-apoptotic mediator and an overexpression of IRS-2 in antral follicles results in reduction of apoptosis with accumulation of follicular cysts $[33,51,52]$. We can assume, in view of evidence, that phosphorylation is a crucial event in regulation of BCL2 members action and it is associated with stimulation of IRS during the activation of nutrient-sensing pathways in the mitochondria glucose metabolism (Figure 3).

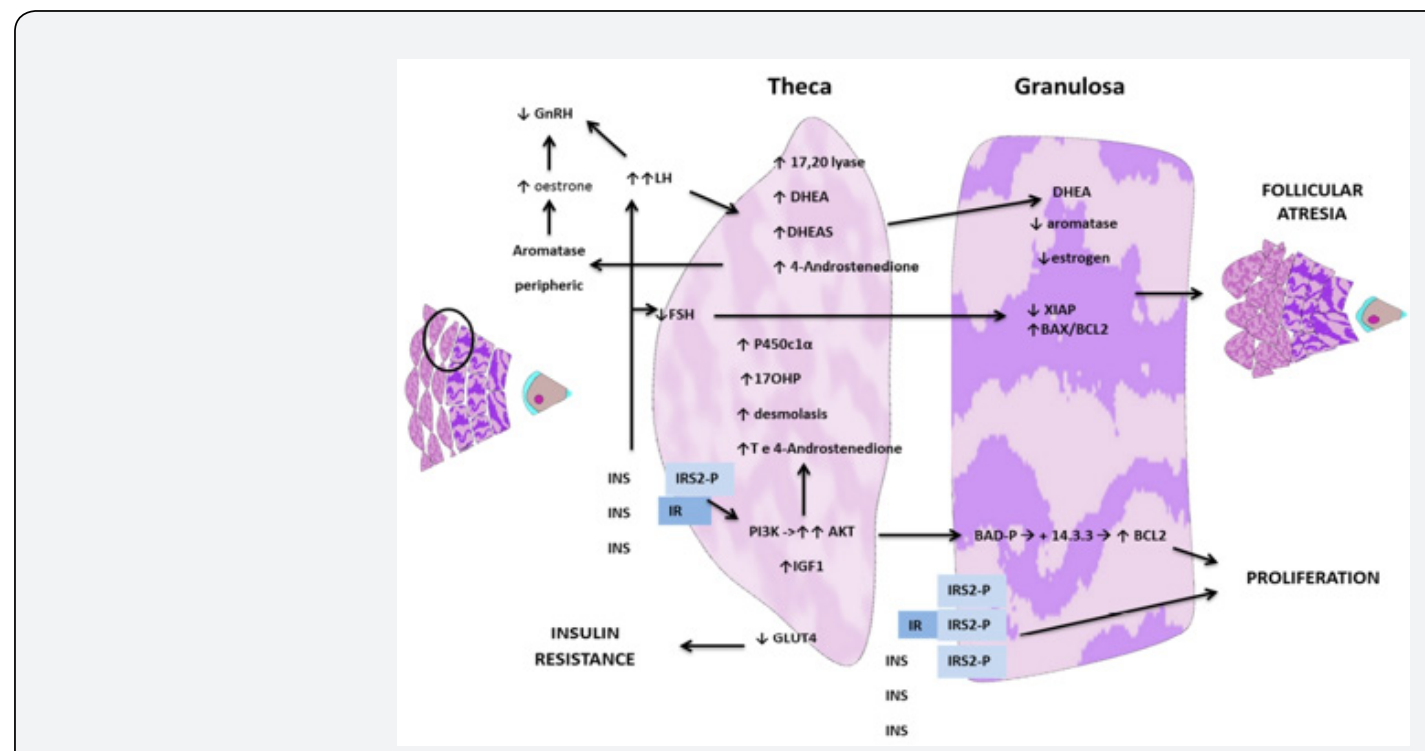

Figure 3: Abronmal expression of BCL2 proteins in hyperandrogenism and hyperinsulinism microenvironment in theca and granulosa cells. GNRH: Gonadotropin-releasing hormone, LH: luteinizing hormone, FSH: follicle-stimulating hormone, DHEA: dehydroepiandrosterone, DHEAS: dehydroepiandrosterone sulphate, P450c1a: cytochrome P450c1a, PI3k: phosphatidylinositol-4,5-bisphosphate 3-kinase, AKT: protein kinase B, GLUT4: glucose transporter type4, IR: Insulin receptor, IRS2: Insulin receptor substratr-2, P: Phosphorilated, 14.3.3: 14.3.3 Proteins, XIAP: X-linked inhibitor of apoptosis proteins, INS: Insulin.

\section{Normal androgen pathway: structures and cellular re- sponses}

Androgens have been considered vital for ovarian function and the correct expression of androgen receptor is essential for normal follicles growth [52]. In particular, dehydroepiandrosterone (DHEA) and its sulfated derivative (DHEAS), are the most abundant circulating steroid hormones in humans and the limiting step for their correct synthesis is the normal activity of the enzyme desmolase which converts cholesterol into pregnenolone, and, subsequently, thought hydroxylase, converts pregnenolone to DHEA rapidly sulfated into DHEAS [53]. More than classical receptor binding, it has been demonstrated that DHEA can interact with Endothelial Nitric Oxide Synthases (ENOs) increasing levels of intracellular Cyclic Guanosine Monophosphate, which would be constitute a specific receptor [54]. However, the androgen receptor (AR), also known as nuclear receptor subfamily 3 , group $\mathrm{C}$, member 4 , is a type of nuclear receptor that is activated by binding either of the androgenic hormones, testosterone, or dihydrotestosterone in the cytoplasm and then trans- locating into the nucleus $[55,56]$. In the ovarian tissue, ARs are widely expressed in theca cells, granulosa cells, oocyte and their expression changes with the follicular development: AR is abundant in pre-antral and antral follicles and decline with follicular maturity, and its concentration is measurable on follicular fluid $[57,58]$. Studies conducted on homozygous androgen receptor (AR)-knockout (ARKO) female mice, that can reveal the precise AR-regulated pathways, demonstrate that androgens level increased AR expression in theca and granulosa cells of pre-antral follicles creating a mechanism of amplification [59]. After interaction between androgen and AR, functions of androgens are mediated by binding with nuclear/genomic receptor (PI3K/Akt pathway) or extra nuclear/non genomic receptor (ARE), whose stimulation increasing the expression of microRNA, directly involved in decreasing pro-apoptotic proteins and in regulation of ovarian growth during follicles development (Figure 2).

Androgens interaction with BCL2 family: During in vitro and in vivo study, normal androgens in ARKO mice ovary increased granulosa cells proliferation so succeeded in mitigation 
of follicular atresia, with increased expression of the anti-apoptotic microRNA (miR-125b), that contributes to androgen-induced follicular survival and is inversely proportional to BAK, BAX and BMF levels in ovary [60]. Moreover, the normal cyclical level of DHEA and DHEAS can act on the granulosa cells the improved expression of BCL2 together with formation of BCL2/ BAX heterodimer, which can stabilize the integrity of mitochondria and protects cells from apoptosis ensuring oocyte vitality [61-63].

Abnormal androgen pathway in ovary: In reproductive-age women, the most commonly diagnosed condition, associated with hyperandrogenism, is PCOS characterized by anovulation, infertility, insulin resistance and hyperandrogenism that affects between 5 and $10 \%$ of women of reproductive age worldwide [64]. PCOS is a cause of oligo-ovulation, rather than anovulation. Apoptosis is the mechanism underlying follicular atresia; it is fundamental for the cyclical growth and regression of follicles in the healthy human ovary. Follicular abnormality in PCOS is characterized by an increased number of pre-antral follicles which is presumably the consequence of intraovarian hyperandrogenism [65]. The presence of 2-5mm follicles gives the typical aspect of multifollicular ovaries at ultrasonography, which is in close relationship with the androgen serum level [66]. In PCOS rat models, excess of androgens, in particular DHEA, increased the expression of BAX in granulosa cells, leading to an imbalance among BCL2 members with a BAX/BCL2 ratio significantly higher and, consequently, an apoptotic response due to a granulosa cell reduction of BCL2 expression $[67,68]$.

Furthermore, another study conducted on immature rat ovary, showed that an administration of testosterone for prolonged exposure leads to a decreased BCL2 levels with important rate of apoptosis in granulosa cells associated with oocytes deformation in pre-antral and antral stage [69]. A prenatal treatment with testosterone, disrupting the intrafollicular steroidal balance in preovulatory follicles $(5-7 \mathrm{~mm})$, is likely to reduce embryonic potential in rhesus monkeys [70] while in sheeps, prenatal testosterone excess in the first 90 days of gestation enhances follicular recruitment, causing disruptions of follicles [71] and in both animal models ovary assume typical characteristics of PCOS. Evaluating these studies during pregnancy, hyperandrogenism seems to influence directly oocyte atresia, while during life, atresia is a direct result of granulosa cell failure. In addition, an example of deregulation in BCL2 expression derived from studies on prostate cancer, where BCL2 expression is up-regulated during the development of hormone-refractory disease, therefore after androgen withdrawal BCL2 expression increases, as a capacity of suppression practised by androgens [72] (Figure 3).

\section{Ovarian cancer and BCL2 family}

Ovarian cancer $(\mathrm{OC})$ is a severe disease affecting the female genital tract. According to the American Cancer Society, a woman has a $1.4 \%$ chance of developing OC during her life [73] Approximately $90 \%$ of the women are over the age of 40 years. For these reasons is desirable and indeed necessary to make an early diagnosis. Majority of patients with OC initially respond to current standard of care that comprises chemotherapy with platinum and taxane agents, but a high percentage of these responders develop chemoresistace, as a result of epigenetic modification induced by chemotherapy or a selection of chemotherapy itself [74]. On a molecular level, estrogen prevent apoptosis through BCL2 up-regulation and also can increase ovarian carcinogenesis through the cytoplasmic estrogen receptor $\beta 2$ (cER $\beta 2$ ) more represented in serous ovarian cancer [75]; whereas progesterone has a pro-apoptotic effect on ovarian epithelium through the modulation of Transforming Growth Factor $\beta$ (TGF $\beta$ ) expression and through the activation of the Fas/Fas Ligand signaling pathway [76]. On the contrary androgens seem to be involved in ovarian carcinogenesis in animal models and testosterone may intensify the ovarian epithelial tumours growth decreasing TGF $\beta$ receptor levels, allowing tumour cells to escape TGF $\beta 1$ mediated growth inhibition, thus promoting ovarian cancer cell proliferation [77].

In this regard, as involved in various tumors, BCL2 function and expression has been also investigated in the earlier stages of ovarian carcinogenesis, and different studies have highlighted that an increase of anti-apoptotic activity, in particular BCL2, after a phosphorylation at serine or threonine residues (S70, S87, and T69) can regulate both cell cycle entry and apoptosis whereas the mechanism is not yet clear [78]. Recent studies indicate that BCL2 overexpression may also promote cancer cell survival, through increased angiogenesis, by upregulating the expression of VEGF (Vascular Endothelial Growth Factor) $[79,80]$. The overexpression of BCL2 contributes to chemoresistance by stabilizing the mitochondrial membrane against apoptotic insults and its expression is higher in the epithelial ovarian cancer tissue in a manner directly proportional to the ability to escape from the guard mechanisms [81]. Data suggest that BCL2 overexpression, alone or in association with CA125, may result in increased levels of BCL2 in body fluids that could represent a novel biomarker for ovarian cancer, being higher in patients with ovarian cancer compared to healthy controls or women with benign gynecologic disease $[82,83]$. In addition, high levels of FSH and FSH-receptor with elevated IRS-2 expression may occur in patients with poor prognosis ovarian cancer and with extragonadic tissue diffusion and cancer proliferation, highlighting a close correlation between FSH, IRS and expression of apoptotic factors [84].

\section{Endometrial pathology and BCL2 family}

BCL2 gene family can have a role in endometrial pathologies. The key of this physiological mechanism is the cellular BCL2/ $\mathrm{BAX}$ ratio. An high BCL2/BAX ratio leads to an increase capacity of resistance to apoptotic stimuli, conversely a low ratio induces cell death; these relations are fundamental for the normal homeostasis in the endometrium during the menstrual cycle [85]. BCL2 function has been also studied in pre-neoplastic and neoplastic condition of endometrium. Endometrial hyperplasia is 
defined as a proliferation of glands of irregular size and shape with an associated increase in the gland/ stromal ratio compared with proliferative endometrium [86]. It was observed that in cyclical endometrium, there was increased expression of BCL2 in the proliferative endometrium phase, while in early secretory endometrium BCL2 had mild expression and only in the mid and late secretory endometrium it was not detectable. However, several earlier studies support the concept that BCL2 is down-regulated in endometrial carcinoma $[87,88]$ while, in hyperplastic endometrium, the BCL2 score showed increased expression, in ascending order of frequency from simple hyperplasia to complex hyperplasia and complex hyperplasia with atypia, that indicate a crescent escape from apoptosis [89]. In addition, in PCOS patients, androgens stimulate an high BAX/BCL2 ratio in endometrium, that potentially is associated with the disruption of endometrial cell cycle; a decrease in cell apoptosis due to a reduction in BCL2 expression during window of implantation may be one of the causes of the reduced endometrial receptivity [90].

\section{Therapeutic Approach}

Considering the important molecular roles of BCL2, it is essential to discuss the possible evidence and effectiveness of therapeutic strategies, which can induce specific blockage or modulation of BCL2 members, since BCL2 alteration is associated with poor response to treatment or infertility. We focused our attention on alteration of insulin and androgen pathway, reviewing the current clinical evidence.

\section{Therapeutic approach for impaired insulin and an- drogen pathway in ovary and endometrium}

Estrogen and progestin: In women with endometriosis, the effect of combined oral contraceptive (COC) on BCL2/BAX ratio was evaluated. Exposure to a monophasic COC for 30 days significantly increases endometrial apoptosis in comparison with pre-treatment levels, both in epithelial and stromal cells; COC administration reverses the abnormal increment in BCL2 expression in patients with endometriosis and induces a major increase in the expression of BAX demonstrating the ability to influence the molecular expression [91]. The effect of COC was also studied in normal and breast cancer cell lines and it was demonstrated that estrogen and progestin agents can differentially modulate the expression of BCL2 and BCLXL, without modifying the gene expression of the BCL2 members but modulating the post-transcriptional phase; in particular, progestin decreases significantly the BCL2 protein levels, while estradiol has the opposite effect. [92]. Moreover studies conducted on rat ovary for the evaluation of long-term effects of treatment with GnRH antagonist or GnRH agonist or estrogen plus progesterone have evaluated as $\mathrm{GnRH}$ angonist and estrogen plus progesterone (estradiol valerate and norethisteron enantate) treatments seem to influence apoptosis in rat the ovary increasing BAX levels and decreasing BCL2 levels leading to follicular atresia $[93,94]$. Also in vitro study on human pancreatic beta cells, medroxyprogesterone acetate seems to induce apoptosis through phosphorylation of BCL2 [95]. Despite these promising evidence on rat ovary, studies on human ovary are needed for a greater understanding of these mechanisms.

Metformin: Metformin is a synthetically derived biguanide that suppresses endogenous glucose output and increases peripheral insulin sensitivity [96,97]. It is used in the management of dysmetabolic disorders and insulin resistance in PCOS woman. The effects of metformin on glucose metabolism seem to be secondary to its actions on the mitochondrial respiratory chain through the inhibition of the mitochondrial respiratory complex I [98]. Regarding ovary, data suggest that metformin leads to activation of AMPK with consequent inhibition of PI3K/Akt/mTOR signalling transduction pathway [99]. Also anti-prolipherative effect of metformin is studied on primary cultures of epithelial ovarian cancer cells, derived from ascitic fluids, and Authors have highlighted that metformin induces apoptosis by down-regulation of BCL2 and BCLXL expression, and up-regulation of BAX and cytochrome c expression $[100,101]$.

Cancer drugs: Finally, regarding cancer lesions, we have a large presence of anti-BCL2 drugs whose aim is to be a potential approach to induce apoptosis in cancer cells or enhancing therapy [102]. ABT-737 [103] is a small molecule inhibitor of BCL2, BCLXL, and BCLW and showed in vitro activity against lymphoma, small cell carcinoma cells, myeloma and acute leukemia. Recently, given the subsequent resistance to this drug, it has been taken into account, as a potential target, Mcl-1 (induced myeloid leukemia cell differentiation protein) [104,105], a member of BCL-2 family; the strategy provides an antisense therapy composed of a single oligonucleotide strand complementary to the target sequence, forming a DNA heteroduplex, exposed to destruction by RNAse and that also showed in vitro promising results in different cancer [106].

Furthermore, the anti-cancer activities of 8-bromo-7-methoxychrysin (BrMC), a novel chrysin analog, induces apoptosis of cisplatin-sensitive and resistant ovarian cancer cells accompanied with the upregulation of BIM (proapoptotic BH3-only) with inhibited expression of p-FOX03a (a Forkhead box transcription factor important in regulation of cellular function) in cells, leading to apoptosis in human ovarian cancer cell line [107]. A carbazole-derivative KSP inhibitor, KPYB10602, which is the most potent of the KSP inhibitors tested in vitro, has in vivo anti-tumor activity in an A2780 human ovarian cancer xenograft model, enhancing the expression of BAX and slightly decreasing BCL2 leading to BAX/BCL2 ratio increased with ROS (reactive oxygen species) production via promotion of cytochrome c release [108]. Except for the traditional therapies, combination of paclitaxel and phytochemical piperine showed promising effect given the increase $\mathrm{Bax} / \mathrm{Bcl}-2$ ratio in human ovarian adenocarcinomas [109]. In addition, considering that IGFs and their receptors play an important roles in regulating the normal biology of ovarian surface epithelial cells and have been implicated in the transformed phenotype of ovarian carcinoma cells, it has been evaluated the action of NVPAEW541 a pyrrolo [2,3-d] pyrimidine 
derivative that is capable of inhibiting the phosphorylation and activation of the downstream pathway components of the IGF-IR with encouraging results [110]. Also a new marker and auspicious targeted therapy is a transcription factor p150Sal2, whose value is low in human ovarian carcinomas, with reduced expression of BAX, resulting in growth arrest and apoptosis [77]. It fundamental to define the mechanisms in which BCL2 is involved in resistance to anti-tumor therapy, in order to allow a greater and better chance to recover.

\section{Conclusion and Future Directions}

Mechanisms of programmed cell death are the basis of a necessary homeostasis of our body and it is the results of a complex balance of signals. In some diseases these patterns can be altered, becoming themselves a source of disease. This occurs in the large family of oncogenes and tumor suppressor genes whose altered operation can lead to serious tissue disorders. It was interesting to note that impaired expression of BCL2 in foetal uterus may result in uterine congenital malformation. Also altered expression of BCL2 family can lead to a wide spectrum of diseases related to the female genital tract, in which BCL2 can be trigger or factor involved secondarily by pre-existing metabolic alterations. In particular, we have analysed the effect of insulin-resistance and hyperandrogenemia on expression of BCL2 members in ovarian follicles and endometrium. The alteration of normal cell growth can lead either to cellular apoptosis or to cellular uncontrolled proliferation. Considering that proliferative stimulus derived from mutation of gene encoding for tumor suppressor or oncogene, it is interesting underline that abnormal metabolic stimuli may exacerbate or speed up these mechanisms and, for these reasons, their consideration, in terms of therapeutic approach, cannot be underestimated. Certainly the connection between hormone alterations and interference with normal cell cycle are much investigated but further studies are necessary to better understand dysmetabolic pattern in which BCL2 members are involved in order to implement, where possible, a direct or indirect therapy aiming to restore the altered balance.

\section{Acknowledgement}

We are grateful to Engr. Fabio Lasorella and Dr. Francesca Letizia for the creation of the figures.

\section{References}

1. Vaux DL, Cory S, Adams JM (1988) Bcl-2 gene promotes haemopoietic cell survival and cooperates with c-myc to immortalize pre-B cells. Nature 335(6189): 440-442.

2. Tsujimoto Y, Croce CM (1986) Analysis of the structure, transcripts, and protein products of bcl-2, the gene involved in human follicular lymphoma. Proc Natl Acad Sci USA 83(14): 5214-5218.

3. Zamzami N, Brenner C, Marzo I, Susin SA, Kroemer G, et al. (1998) Subcellular and submitochondrial mode of action of Bcl-2-like oncoproteins. Oncogene 16(17): 2265-2282.

4. Youle RJ, Strasser A (2008) The BCL-2 protein family: opposing activities that mediate cell death. Nat Rev Mol Cell Biol 9(1): 47-59.

5. Hardwick JM, Soane L (2013) Multiple functions of BCL-2 family proteins. Cold Spring Harb Perspect Biol 5(2).
6. Muchmore SW, Sattler M, Liang H, Meadows RP, Harlan JE, et al. (1996) X-ray and NMR structure of human Bcl-xL, an inhibitor of programmed cell death. Nature 381(6580): 335-341.

7. Certo M, Moore DGV, Nishino M, Wei G, Korsmeyer S, et al. (2006) Mitochondria primed by death signals determine cellular addiction to antiapoptotic BCL-2 family members. Cancer Cell 9(5): 351-365.

8. Kaufmann T, Tai L, Ekert PG, Huang DC, Norris F, et al. (2007) The BH3-only protein bid is dispensable for DNA damage- and replicative stress-induced apoptosis or cell-cycle arrest. Cell 129(2): 423-433.

9. Kaufmann T, Schlipf S, Sanz J, Neubert K, Stein R, et al. (2003) Characterization of the signal that directs $\mathrm{Bcl}-\mathrm{xL}$, but not $\mathrm{Bcl}-2$, to the mitochondrial outer membrane. J Cell Biol 160(1): 53-64.

10. Edlich F, Banerjee S, Suzuki M, Cleland MM, Arnoult D, et al. (2011) Bcl$\mathrm{x}(\mathrm{L})$ retrotranslocates Bax from the mitochondria into the cytosol. Cell 145(1): 104-116.

11. Gibson L, Holmgreen SP, Huang DC, Bernard O, Copeland NG, et al. (1996) Bcl-w, a novel member of the bcl-2 family, promotes cell survival. Oncogene 13(4): 665-675.

12. Du C, Fang M, Li Y, Li L, Wang X, et al. (2000) Smac, a mitochondrial protein that promotes cytochrome c-dependent caspase activation by eliminating IAP inhibition. Cell 102(1): 33-42.

13. Zou H, Henzel WJ, Liu X, Lutschg A, Wang X, et al. (1997) Apaf-1, a human protein homologous to C. elegans CED-4, participates in cytochrome c-dependent activation of caspase-3. Cell 90(3): 405-413.

14. Li P, Nijhawan D, Budihardjo I, Srinivasula SM, Ahmad M, et al. (1997) Cytochrome c and dATP-dependent formation of Apaf-1/caspase- 9 complex initiates an apoptotic protease cascade. Cell 91(4): 479-489.

15. Griffiths GJ, Dubrez L, Morgan CP, Jones NA, Whitehouse J, et al. (1999) Cell damage-induced conformational changes of the pro-apoptotic protein Bak in vivo precede the onset of apoptosis. J. Cell Biol 144(5): 903-914.

16. Annis MG, Soucie EL, Dlugosz PJ, Cruz-Aguado JA, Penn LZ, et al. (2005) Bax forms multispanning monomers that oligomerize to permeabilize membranes during apoptosis. EMBO J 24(12): 2096-2103.

17. Adrain C, Creagh EM, Martin SJ (2001) Apoptosis-associated release of Smac/DIABLO from mitochondria requires active caspases and is blocked by Bcl-2. EMBO J 20(23): 6627-6636.

18. Toder V, Carp H, Fein A, Torchinsky A (2002) The role of pro- and anti-apoptotic molecular interactions in embryonic maldevelopment. Am J Reprod Immunol 48(4): 235-244.

19. Chandler MT, Machan S, Cooperberg P, Harris AC, Chang SD, et al. (2009) Müllerian duct anomalies: from diagnosis to intervention. Br J Radiol 82(984): 1034-1042.

20. Lee DM, Osathanondh R, Yen J (1998) Localization of Bcl-2 in the human fetal mullerian tract. Fertil Steril 70(1): 135-140.

21. Chan YY, Jayaprakasan K, Zamora J, Thornton JC, Raine-Fenning N, et al. (2011) The prevalence of congenital uterine anomalies in unselected and high-risk populations: a systematic review. Hum Reprod Update 17(6): 761-771.

22. Taguchi A, White MF (2008) Insulin-like signaling, nutrient homeostasis, and life span. Annu Rev Physiol 70: 191-212.

23. White MF (2003) Insulin signaling in health and disease. Science 302(5651): 1710-1711.

24. Meyts DP (2008) The insulin receptor: a prototype for dimeric, allosteric membrane receptors? Trends Biochem Sci 33(8): 376-384.

25. Seino S, Seino M, Nishi S, Bell GI (1989) Structure of the human insulin receptor gene and characterization of its promoter. Proc Natl Acad Sci USA 86(1): 114-118. 
26. Bjornholm M, He AR, Attersand A, Lake S, Liu SC, et al. (2002) Absence of functional insulin receptor substrate-3 (IRS-3) gene in humans. Diabetologia 45(12): 1697-1702.

27. Backer JM, Myers JMG, Shoelson SE, Chin DJ, Sun XJ, et al. (1992) MF Phosphatidylinositol 3'-kinase is activated by association with IRS-1 during insulin stimulation. EMBO J 11(9): 3469-3479.

28. Figueiredo-Silva AC, Panserat S, Kaushik S, Geurden I, Polakof S, et al. (2012) High levels of dietary fat impair glucose homeostasis in rainbow trout. J Exp Biol 215(pt 1): 169-178.

29. Dai N, Christiansen J, Nielsen FC, Avruch J (2013) mTOR complex 2 phosphorylates IMP1 cotranslationally to promote IGF2 production and the proliferation of mouse embryonic fibroblasts. Genes Dev 27(3): 301-312.

30. Shepherd PR, Withers DJ, Siddle K (1998) Phosphoinositide 3-kinase: the key switch mechanism in insulin signalling. Biochem J 333(pt 3): 471-490.

31. Farhang-Fallah J, Randhawa VK, Nimnual A, Klip A, Bar-Sagi D, et al. (2002) The pleckstrin homology (PH) domain-interacting protein couples the insulin receptor substrate $1 \mathrm{PH}$ domain to insulin signaling pathways leading to mitogenesis and GLUT4 translocation. Mol Cell Biol 22(20): 7325-7336.

32. Sun XJ, Wang LM, Zhang Y, Yenush L, Myers MG, et al. (1995) Role of IRS-2 in insulin and cytokine signalling. Nature 377(6545): 173-177.

33. Wu X, Sallinen K, Anttila L, Mäkinen M, Luo C, et al. (2000) Expression of insulin-receptor substrate-1 and -2 in ovaries from women with insulin resistance and from controls. Fertil Steril 74: 564-572.

34. Hay N, Sonenberg N (2004) Upstream and downstream of mTOR Genes Dev 18(16): 1926-1945.

35. Eskander RN, Tewari KS (2014) Exploiting the therapeutic potential of the PI3K-AKT-mTOR pathway in enriched populations of gynecologic malignancies. Expert Rev Clin Pharmacol 7(6): 847-858.

36. Kuhajda FP (2008) AMP-activated protein kinase and human cancer: cancer metabolism revisited. Int J Obes (Lond) 32(Suppl 4): 36-41.

37. Lu X, Guo S, Cheng Y, Kim JH, Feng Y, et al. (2017) Stimulation of ovarian follicle growth after AMPK inhibition. Reproduction 153(5): 683-694.

38. Rattan R, Giri S, Singh AK, Singh I (2005) 5-Aminoimidazole-4-carboxamide-1-beta-D-ribofuranoside inhibits cancer cell proliferation in vitro and in vivo via AMP-activated protein kinase. J Biol Chem 280(47): 39582-39593.

39. Peso DL, González-García M, Page C, Herrera R, Nuñez G, et al. (1997) Interleukin-3-induced phosphorylation of BAD through the protein kinase Akt. Science 278(5338): 687-689.

40. Tanaka S, Wands JR (1996) Insulin receptor substrate 1 overexpression in human hepatocellular carcinoma cells prevents transforming growth factor beta1-induced apoptosis. Cancer Res 56(15): 3391-3394.

41. Tan Y, Demeter MR, Ruan H, Comb MJ (2000) Ser-155 phosphorylation regulates $\mathrm{BAD} / \mathrm{Bcl}-\mathrm{XL}$ interaction and cell survival. J Biol Chem 275(33): 25865-25869.

42. Danial NN (2008) BAD: undertaker by night, candyman by day. Oncogene 27(Suppl 1): 53-70.

43. Scaramuzzi RJ, Zouaidi N, Menassol JB, Dupont J (2015) The effects of intravenous, glucose versus saline on ovarian follicles and their levels of some mediators of insulin signalling. Reprod Biol Endocrinol 13: 6.

44. Samoto T, Maruo T, Ladines-Llave CA, Matsuo H, Deguchi J, et al. (1993) Insulin receptor expression in follicular and stromal compartments of the human ovary over the course of follicular growth, regression and atresia. Endocr J 40(6): 715-726.

45. Peruzzi F, Prisco M, Dews M, Salomoni P, Grassilli E, et al. (1999) Mul- tiple signaling pathways of the insulin like growth factor 1 receptor in protection from apoptosis. Mol Cell Bio 19(10): 7203-7215.

46. Neganova I, Al-Qassab H, Heffron H, Selman C, Choudhury AI, et al. (2007) Role of central nervous system and ovarian insulin receptor substrate 2 signaling in female reproductive function in the mouse. Biol Reprod 76(6): 1045-1053.

47. Shaw LM (2011) The insulin receptor substrate (IRS) proteins: at the intersection of metabolism and cancer. Cell Cycle 10(11): 1750-1756.

48. Anjali G, Kaur S, Lakra R, Taneja J, Kalsey GS, et al. (2015) FSH stimulates IRS-2 expression in human granulosa cells through cAMP/SP1, an inoperative FSH action in PCOS patients. Cell Signal 27(12): 24522466.

49. Kaur S, Anjali G, Bhardwaj P, Taneja J, Singh R, et al. (2015) Data in support of FSH induction of IRS-2 in human granulosa cells: Mapping the transcription factor binding sites in human IRS-2 promoter. Data Brief 6: 162-167.

50. Dupont J, Scaramuzzi RJ (2016) Insulin signalling and glucose transport in the ovary and ovarian function during the ovarian cycle. Biochem J 473(11): 1483-1501.

51. Sesti G, Federici M, Hribal ML, Lauro D, Sbraccia P, et al. (2001) Defects of the insulin receptor substrate (IRS) system in human metabolic disorders. FASEB J 15(12): 2099-2111.

52. Burger HG (2002) Androgen production in women. Fertil Steril 77(Suppl 4): S3-5.

53. Rainey WE, Carr BR, Sasano H, Suzuki T, Mason JI, et al. (2002) Dissecting human adrenal androgen production. Trends Endocrinol Metab 13(6): 234-239.

54. Simoncini T, Mannella P, Fornari L, Varone G, Caruso A, et al. (2003) Dehydroepiandrosterone modulates endothelial nitric oxide synthesis via direct genomic and nongenomic mechanisms. Endocrinology 144(8): 3449-3455.

55. Roy AK, Lavrovsky Y, Song CS, Chen S, Jung MH, et al. (1999) Regulation of androgen action. Vitam Horm 55: 309-352.

56. Lu NZ, Wardell SE, Burnstein KL, Defranco D, Fuller PJ, et al. (2006) International Union of Pharmacology. LXV. The pharmacology and classification of the nuclear receptor superfamily: glucocorticoid, mineralocorticoid, progesterone, and androgen receptors. Pharmacol Rev 58(4): 782-797.

57. Haning RV, Hackett RJ, Flood CA, Loughlin JS, Zhao QY, et al. (1993) Plasma dehydroepiandrosterone sulfate serves as a prehormone for $48 \%$ of follicular fluid testosterone during treatment with menotropins. J Clin Endocrinol Metab 76(5): 1301-1307.

58. Otala M, Mäkinen S, Tuuri T, Sjöberg J, Pentikäinen V, et al. (2004) Effects of testosterone, dihydrotestosterone, and 17beta-estradiol on human ovarian tissue survival in culture. Fertil Steril 82(Suppl 3): 10771085.

59. Cheng XB, Jimenez M, Desai R, Middleton LJ, Joseph SR, et al. (2013) Characterizing the neuroendocrine and ovarian defects of androgen receptor-knockout female mice. Am J Physiol Endocrinol Metab 305(6): E717-726.

60. Sen A, Prizant H, Light A, Biswas A, Hayes E, et al. (2014) Androgens regulate ovarian follicular development by increasing follicle stimulating hormone receptor and microRNA-125b expression. Proc Natl Acad Sci USA 111(8): 3008-3013.

61. Tilly JL, Tilly KI, Kenton ML, Johnson AL (1995) Expression of members of the bcl-2 gene family in the immature rat ovary: equine chorionic gonadotropin mediated inhibition of granulosa cell apoptosis is associated with decreased bax and constitutive bcl-2 and bcl-xlong messenger ribonucleic acid levels. Endocrinology 136(1): 232-224. 
62. Haldar S, Basu A, Croce CM (1997) Bcl2 is the guardian of microtubule integrity. Cancer Res 57(2): 229-233.

63. Kuan CY, Roth KA, Flavell RA, Rakic P (2000) Mechanisms of programmed cell death in the developing brain. Trends Neurosci 23(7): 291-297.

64. The Rotterdam ESHRE/ASRM-Sponsored PCOS Consensus Workshop Group (2004) Revised 2003 consensus on diagnostic criteria and long term health risks related to polycystic ovary syndrome. Fertil Steril 81(1): 19-25.

65. Vendola KA, Zhou J, Adesanya O0, Weil SJ, Bondy CA, et al. (1998) Androgens stimulate early stages of follicular growth in the primate ovary. J Clin Invest 101(12): 2622-2629.

66. Jonard S, Robert Y, Cortet-Rudelli C, Pigny P, Decanter C, et al. (2003) Ultrasound examination of polycystic ovaries: is it worth counting the follicles? Hum Reprod 18(3): 598-603.

67. Bas D, Abramovich D, Hernandez F, Tesone M (2011) Altered expression of Bcl-2 and Bax in follicles within dehydroepiandrosterone-induced polycystic ovaries in rats. Cell Biol Int 35(5): 423-429.

68. Datta SR, Ranger AM, Lin MZ, Sturgill JF, Ma YC, et al. (2002) Survival factor-mediated BAD phosphorylation raises the mitochondrial threshold for apoptosis. Dev Cell 3(5): 631-643.

69. Beloosesky R, Gold R, Almog B, Sasson R, Dantes A, et al. (2004) Induction of polycystic ovary by testosterone in immature female rats: Modulation of apoptosis and attenuation of glucose/insulin ratio. Int J Mol Med 14(2): 207-215.

70. Dumesic DA, Schramm RD, Peterson E, Paprocki AM, Zhou R, et al. (2002) Impaired developmental competence of oocytes in adult prenatally androgenized female rhesus monkeys undergoing gonadotropin stimulation for in vitro fertilization. J Clin Endocrinol Metab 87(3): 1111-1119.

71. Salvetti NR, Ortega HH, Veiga-Lopez A, Padmanabhan V (2012) Developmental programming: impact of prenatal testosterone excess on ovarian cell proliferation and apoptotic factors in sheep. Biol Reprod 87(1): 1-10.

72. Fuzio P, Ditonno P, Lucarelli G, Battaglia M, Bettocchi C, et al. (2011) Androgen deprivation therapy affects BCL-2 expression in human prostate cancer. Int J Oncol 39(5): 1233-1242.

73. American Cancer Society (2017) Cancer Facts and Figures 2017. American Cancer Society, Atlanta, Georgia.

74. Morgan RJ, Alvarez RD, Armstrong DK, Boston B, Chen LM, et al. (2008) National Comprehensive Cancer Network. Ovarian cancer. Clinical practice guidelines in oncology. J Natl Compr Canc Netw 6: 766-794.

75. Ciucci A, Zannoni GF, Travaglia D, Scambia G, Gallo D, et al. (2015) Mitochondrial estrogen receptor $\beta 2$ drives antiapoptotic pathways in advanced serous ovarian cancer. Hum Pathol 46(8): 1138-1146.

76. Choi KC, Kang SK, Tai CJ, Auersperg N, Leung PC, et al. (2001) Estradiol up-regulates antiapoptotic Bcl-2 messenger ribonucleic acid and protein in tumorigenic ovarian surface epithelium cells. Endocrinology 142(6): 2351-2360.

77. Li L, Wu J, Luo M, Sun Y, Wang G, et al. (2016) The effect of heat stress on gene expression, synthesis of steroids, and apoptosis in bovine granulosa cells. Cell Stress Chaperones 21(3): 467-475.

78. Deng X, Gao F, Flagg T, May WS (2004) Mono- and multisite phosphorylation enhances Bcl2's antiapoptotic function and inhibition of cell cycle entry functions. Proc Natl Acad Sci U S A 101(1): 153-158.

79. Nor JE, Christensen J, Liu J, Peters M, Mooney DJ, et al. (2001) Up-Regulation of Bcl-2 in microvascular endothelial cells enhances intratumoral angiogenesis and accelerates tumor growth. Cancer Res 61(5) 2183-2188.
80. Karl E, Warner K, Zeitlin B, Kaneko T, Wurtzel L, et al. (2005) Bcl-2 acts in a proangiogenic signaling pathway through nuclear factor-kappaB and CXC chemokines. Cancer Res 65(12): 5063-5069.

81. Chan WY, Cheung KK, Schorge JO, Huang LW, Welch WR, et al. (2000) Bcl-2 and p53 protein expression, apoptosis and p53 mution in human epithelial ovarian cancer. Am Pathol 156(2): 409-417.

82. Camlica H, Duranyildiz D, Tas F, Yasasever V (2008) Statistical interpretation of CA125 and Bcl-2 in serum of patients with late stage ovarian cancer. Am J Clin Oncol 31(6): 585-588.

83. Anderson NS, Bermudez Y, Badgwell D, Chen R, Nicosia SV, et al. (2009) Urinary levels of Bcl-2 are elevated in ovarian cancer patients. Gynecol Oncol 112(1): 60-67.

84. Perales-Puchalt A, Svoronos N, Rutkowski MR, Allegrezza MJ, Tesone AJ, et al. (2017) Follicle-Stimulating Hormone Receptor Is Expressed by Most Ovarian Cancer Subtypes and Is a Safe and Effective Immunotherapeutic Target. Clin Cancer Res 23(2): 441-453.

85. Tao XJ, Tilly KI, Maravei DV, Shifren JL, Krajewski S, et al. (1997) Differential expression of members of the bcl-2 gene family in proliferative and secretory human endometrium: glandular epithelial cell apoptosis is associated with increased expression of bax. J Clin Endocrinol Metab 82(8): 2738-2746.

86. Kounelis S, Kapranos N, Kouri E, Coppola D, Papadaki H, et al. (2000) Immunohistochemical profile of endometrial adenocarcinoma: a study of 61 cases and review of the literature. Mod Pathol 13: 379-388.

87. Henderson GS, Brown KA, Perkins SL, Abbott TM, Clayton F, et al. (1996) Bcl-2 is down-regulated in atypical endometrial hyperplasia and adenocarcinoma. Mod Pathol 9(4): 430-438.

88. Niemann TH, Trgovac TL, McGaughy VR, Vaccarello L (1996) Bcl-2 expression in endometrial hyperplasia and carcinoma. Gynecol Oncol 63(3): 318-322.

89. Peiro G, Diebold J, Baretton GB, Kimmig R, Lohrs U, et al. (2001) Cellular apoptosis susceptibility gene expression in endometrial carcinoma: correlation with Bcl-2, Bax, and caspase-3 expression and outcome. Int J Gynecol Pathol 20(4): 359-367.

90. Yan L, Wang A, Chen L, Shang W, Li M, et al. (2012) Expression of apoptosis-related genes in the endometrium of polycystic ovary syndrome patients during the window of implantation. Gene 506(2): 350-354.

91. Meresman GF, Augé L, Barañao RI, Lombardi E, Tesone M, et al. (2002) Oral contraceptives suppress cell proliferation and enhance apoptosis of eutopic endometrial tissue from patients with endometriosis. Fertil Steril 77(6): 1141-1147.

92. Simões BM, Alferez DG, Howell SJ, Clarke RB (2015) The role of steroid hormones in breast cancer stem cells. Endocr Relat Cancer 22(6): T177-186.

93. Parborell F, Irusta G, Vitale A, Gonzales O, Pecci A, et al. (2005) Gonadotropin-releasing hormone antagonist antide inhibits apoptosis of preovulatory follicle cells in rat ovary. Biol Reprod 72(3): 659-666.

94. Saatli B, Kizildag S, Posaci C, Dogan E, Koyuncuoglu M, et al. (2009) Long-term effects of GnRH agonist, GnRH antagonist, and estrogen plus progesterone treatment on apoptosis related genes in rat ovary. Fertil Steril 91(5 Suppl): S2006-2011.

95. Abe M, Yamashita J, Ogawa M (2000) Medroxyprogesterone acetate inhibits human pancreatic carcinoma cell growth by inducing apoptosis in association with Bcl-2 phosphorylation. Cancer 88(9): 2000-2009.

96. Stumvoll M, Nurjhan N, Perriello G, Dailey G, Gerich JE, et al. (1995) Metabolic effects of metformin in non-insulin-dependent diabetes mellitus. N Engl J Med 333(9): 550-554.

97. Fery F, Plat L, Balasse EO (1997) Effects of metformin on the pathways of glucose utilization after oral glucose in non-insulin-dependent diabetes mellitus patients. Metabolism 46(2): 227-233. 
98. Li Y, Xu S, Mihaylova MM, Zheng B, Hou X, et al. (2011) AMPK phosphorylates and inhibits SREBP activity to attenuate hepatic steatosis and atherosclerosis in diet-induced insulin-resistant mice. Cell Metab 13(4): 376-388.

99. Markman B, Dienstmann R, Tabernero J (2010) Targeting the PI3K/ Akt/mTOR pathway-beyond rapalogs. Oncotarget 1(7): 530-543.

100. Patel S, Kumar L, Singh N (2015) Metformin and epithelial ovarian cancer therapeutics. Cell Oncol (Dordr) 38(5): 365-375.

101. Yasmeen A, Beauchamp MC, Piura E, Segal E, Pollak M, et al. (2011) Induction of apoptosis by metformin in epithelial ovarian cancer: involvement of the Bcl-2 family proteins. Gynecol Oncol 121(3): 492 498.

102. Shibu T, Bridget AQ Swadesh KD, Rupesh D, Luni E, et al. (2013) Targeting the Bcl-2 Family for Cancer Therapy. Expert Opin Ther Targets 17(1): 61-75

103. Delft VMF, Wei AH, Mason KD, Vandenberg CJ, Chen L, et al. (2006) The BH3 mimetic ABT-737 targets selective Bcl-2 proteins and efficiently induces apoptosis via Bak/Bax if Mcl-1 is neutralized. Cancer cell 10(5): 389-399.

104. Kaufmann SH, Karp JE, Svingen PA, Krajewski S, Burke PJ, et al. (1998) Elevated expression of the apoptotic regulator Mcl-1 at the time of leukemic relapse. Blood 91(3): 991-1000.
105. Schwickart M, Huang X, Lill JR, Liu J, Ferrando R, et al. (2010) Deubiquitinase USP9X stabilizes MCL1 and promotes tumour cell survival. Nature 463(7277): 103-107.

106. Sieghart W, Losert D, Strommer S, Cejka D, Schmid K, et al. (2006) Mcl-1 overexpression in hepatocellular carcinoma: a potential target for antisense therapy. Journal of hepatology 44(1): 151-157.

107. Ding Q, Chen Y, Zhang Q, Guo Y, Huang Z, et al. (2015) 8-bromo-7-methoxychrysin induces apoptosis by regulating Akt/FOXO3a pathway in cisplatin-sensitive and resistant ovarian cancer cells. Mol Med Rep 12(4): 5100-5108.

108. Takenaga M, Yamamoto Y, Takeuchi T, Ohta Y, Tokura Y, et al. (2015) Potential new chemotherapy strategy for human ovarian carcinoma with a novel KSP inhibitor. Biochem Biophys Res Commun 463(3): 222-228.

109. Pal MK, Jaiswar SP, Srivastav AK, Goyal S, Dwivedi A, et al. (2016) Synergistic effect of piperine and paclitaxel on cell fate via cyt-c, Bax/ Bcl-2-caspase-3 pathway in ovarian adenocarcinomas SKOV-3 cells. Eur J Pharmacol 791: 751-762.

110. Gotlieb WH, Bruchim I, Gu J, Shi Y, Camirand A, et al. (2006) Insulin-like growth factor receptor I targeting in epithelial ovarian cancer Gynecol Oncol 100(2): 389-396.

\section{Your next submission with Juniper Publishers will reach you the below assets}

- Quality Editorial service

- Swift Peer Review

- Reprints availability

- E-prints Service

- Manuscript Podcast for convenient understanding

- Global attainment for your research

- Manuscript accessibility in different formats

( Pdf, E-pub, Full Tsext, Audio)

- Unceasing customer service

Track the below URL for one-step submission https://juniperpublishers.com/online-submission.php 